http://dx.doi.org/10.1590/1678-4162-7494

Arq. Bras. Med. Vet. Zootec., v.67, n.3, p.655-663, 2015

\title{
Intraoperative ultrasonography of the vertebral canal in dogs
}

[Ultrassonografia intraoperatória do canal vertebral em cães]

M.A. Bonelli, E.A. Tudury, C.R.O. Santos, B.M. Araújo, C.C. Diogo, A.C. Silva, F.S. Costa

Universidade Federal de Pernambuco - Recife, PE

\begin{abstract}
Intraoperative ultrasound (IOS) can provide details on various conditions of the spinal cord and vertebral canal. The aim of the present study was to evaluate the feasibility of using IOS in dogs undergoing spinal surgery and to describe the main findings. The vertebral canal of 21 dogs was examined with intraoperative ultrasonography: 13 underwent spinal surgery for removal of herniated intervertebral disc material, three for stabilization of vertebral fracture/luxation, two for removal of vertebral neoplasia, and three for cauda equina decompression. Particular attention was given to signs of cord compression. Intraoperative ultrasonography was feasible and useful in dogs undergoing surgery for spinal cord or cauda equina decompression and fracture stabilization. It was not paramount for locating the compression when this had been done via computed tomography (CT), but it showed alterations in spinal cord parenchyma not observed on $\mathrm{CT}$ and also confirmed adequate decompression of the spinal cord. The main advantages of intraoperative ultrasonography were estimation of vascularization and extent of spinal cord lesion. Most importantly, it allowed real time evaluation of the spinal cord and vertebral canal, which permits the modification of the surgical procedure.
\end{abstract}

Keywords: neurology, ultrasound, spinal cord

\section{RESUMO}

A ultrassonografia intraoperatória pode fornecer detalhes sobre diversas condições da medula espinal e canal vertebral. $O$ objetivo deste trabalho foi avaliar a viabilidade da utilização da ultrassonografia intraoperatória em cães submetidos à cirurgia espinomedular e descrever os principais achados. O canal vertebral de 21 cães foi examinado com ultrassonografia intraoperatória - 13 foram submetidos à cirurgia para remoção de material de disco herniado, três para estabilização de fratura/luxação vertebral, dois para remoção de neoplasia vertebral e três para descompressão de cauda equina. Atenção especial foi dada a sinais de compressão medular. A ultrassonografia intraoperatória foi viável $e$ útil em cães submetidos a cirurgia para descompressão da medula espinal ou cauda equina $e$ estabilização de fratura. Apesar de não ser indispensável para localização da compressão quando isso havia sido feito através de tomografia computadorizada (TC), demonstrou alterações no parênquima que não haviam sido observadas pela TC e confirmou a adequada descompressão da medula espinhal. As principais vantagens da ultrassonografia intraoperatória foram: estimar a vascularização e a extensão da lesão medular. Principalmente, permitiu uma avaliação em tempo real da medula espinal e do canal vertebral, o que permite modificação do procedimento cirúrgico.

Palavras-chave: neurologia, ultrassonografia, medula espinal

\section{INTRODUCTION}

Ultrasonography is considered one of the best options for direct intraoperative observation of the vertebral canal and spinal cord regarding the presence of alterations (Galloway et al., 1999). It is a non-invasive technique, with no contraindications (Naish et al., 2003). Due to its bony cover, intraoperative ultrasound (IOS) of the spinal cord must be performed after procedures such as ventral slots, laminectomies or hemilaminectomies (Nakayama, 1993). 
Intraoperative ultrasound can provide details on various conditions of the spinal cord and vertebral canal (Tanaka et al., 2005), but it is used mainly in situations where there is spinal compression, such as intervertebral disc disease (IVDD), stenosis of the vertebral canal, vertebral fractures, and foreign bodies in the vertebral canal (Nanai et al., 2007).

The aim was to evaluate the feasibility, advantages and disadvantages of using intraoperative ultrasound in dogs undergoing spinal surgery due to intervertebral disc disease, vertebral fractures/luxations, vertebral neoplasia, and cauda equina decompression and to describe the main findings in each.

\section{MATERIAL AND METHODS}

The vertebral canal of 21 dogs was examined with IOS between October 2011 and April 2013. The dogs underwent spinal surgery for removal of herniated intervertebral disc material, reduction and stabilization of vertebral fractures/luxations, decompression of cauda equina, or removal of neoplasia. An $8 \mathrm{MHz}$ convex transducer [MyLab 30 GOLD CV, Esaote, Italy] was used to obtain gray-scale images in all dogs. All procedures were approved by the Ethics Committee of the Federal Rural University of Pernambuco - UFRPE (Protocol n. 008/2012).

Six laminectomies and 15 hemilaminectomies were performed to allow visualization of the vertebral canal. Rongeurs were used to remove bone. Choice and extension of the bony defect was dependent upon necessity and determined by the surgeon. Once an adequate window was obtained, the area was lavaged and filled with sterile saline to allow ultrasonographic evaluation.

For preparing the transducer, a section of the transducer cable closest to the probe was wrapped in sterile aluminum foil, then covered with a sterile cotton cover made from reusable surgical drapes, and tied off at both ends. The transducer head was then covered with two sterile surgical gloves lined with sterile ultrasound gel and tied off with gauze or elastic wrap. The orientation of the transducer was checked by running a gloved finger over the covered probe.
The surgical field was filled with warm sterile saline, and the transducer head (within the sterile gloves) was immersed into the liquid. Sagittal and oblique sagittal images of the spinal cord were obtained in B-mode through the laminectomy and hemilaminectomy windows, respectively. Transverse images were also obtained in 18 dogs, and color Doppler was used in 17 dogs. Data regarding the characteristics of the spinal canal, spinal cord or cauda equina, and eventual abnormalities were recorded. When possible, a second ultrasonographic exam was performed to evaluate adequate decompression of the spinal cord.

Thirteen dogs presented intervertebral disc extrusion diagnosed via computed tomography $(10 / 13)$ or myelography (3/13). Following hemilaminectomy, they were examined for signs of spinal compression (namely; inability to visualize the central canal and unevenness of the hyperechoic lines that represent the meninges and central canal), presence of material within the vertebral canal, spinal echogenicity, and vascularization.

Three dogs were submitted to surgery for stabilization of fracture and luxation of the thoracolumbar spine between $\mathrm{T}_{11}-\mathrm{L}_{6}$. Radiographs were obtained to confirm diagnosis. They were evaluated for signs of spinal compression, alignment of the floor of the vertebral canal, presence of bone fragments within the vertebral canal, and vascularization.

Three dogs presented chronic pain and neurological deficits following previous fracture/luxation of $\mathrm{L}_{7}-\mathrm{S}_{1}$ and underwent surgery for decompression of cauda equina. Preoperative imaging consisted of radiographs (2 of 3 ) and computed tomography exam (1 of 3 ). They were examined for the presence of fragments within the vertebral canal, alignment of the floor of the vertebral canal at $\mathrm{L}_{7}-\mathrm{S}_{1}$, and visualization of the nerve roots or conus medullaris.

Two dogs presented signs of progressive spinal cord compression. After a presumptive diagnosis of neoplasia via computed tomography in one dog and radiographs in the other, they were submitted to surgery for decompression and biopsy. 


\section{RESULTS AND DISCUSSION}

Intraoperative ultrasonography was performed in 21 of 37 dogs that underwent spinal surgery between October 2011 and April 2013. Of the 16 dogs without IOS performed, five had vertebral fracture and/or luxation that was reduced and stabilized without a laminectomy or hemilaminectomy, making IOS impossible. The other 11 were eligible for IOS, but did not have it performed due to scheduling conflicts related to availability of either the ultrasound device or qualified imaging personnel.

Intraoperative ultrasonography was able to provide information regarding the vertebral canal and spinal cord in $18 \mathrm{dogs}$ and regarding the vertebral canal at the region of the cauda equina in three dogs. It enabled identification of the spinal cord and provided information on compression, decompression, and echogenicity, particularly by allowing visualization of the dura mater, central canal and vascularization (with the use of color Doppler). This was consistent with previous reports using Power Doppler (Nakayama, 1993; Nanai et al., 2007). Though not as sensitive, color Doppler was able to identify larger vessels nurturing the spinal cord.

Signs of spinal compression were defined as the absence of the subarachnoid space and central canal (Nakayama, 1993) and uneven echogenic lines representing the dura mater. When a second visualization was possible, the presence of the central canal, parallel lines, and vascularization were considered to be indicative of adequate decompression.

Disc extrusions occurred at the following segments of the spinal cord: cervical (two, between $\mathrm{C}_{2}$ and $\mathrm{C}_{5}$ ), thoracic (five, between $\mathrm{T}_{11}$ and $\mathrm{T}_{13}$ ), thoracolumbar (one at $\mathrm{T}_{13}-\mathrm{L}_{1}$ ) and lumbar (one at $\mathrm{L}_{1-2}$, three at $\mathrm{L}_{2-3}$ and one at $\mathrm{L}_{3-4}$ ). There was no significant difference between the ultrasonographic appearances of each segment.

Intervertebral disc material within the vertebral canal was observed as a hyperechoic, heterogenous, amorphous mass. Material was observed ventrally in relation to the spinal cord in six of the 13 dogs. In the other seven dogs the material was seen on the surgical opening (between the transducer and the spinal cord).
Spinal cord compression, characterized by inability to visualize the central canal and/or deviation of the parallel hyperechoic lines representing the dura mater, was observed in 11/13 dogs (Figure 1). In 7/13, where the central canal had been only partially identified initially, it was better observed after removal of the disc material (Figure 2). In four dogs where the central canal had not been visualized in the initial scan, it was partially visualized in two and adequately visualized in the other two after removal of the disc material. There was no second ultrasonographic examination in two dogs.

Transverse images were obtained in 12 of the 13 dogs with disc extrusion. In three of these, visualization was not adequate to aid in identifying alterations. The central canal, when visible, appeared as a small hyperechoic circular area in the center of the spinal cord (Fig. 3). The transverse images helped better delimitate areas of altered echogenicity within the spinal cord parenchyma (Figure 4).

Residual disc material was discovered in three of the 13 dogs after extension of the hemilaminectomy. In two dogs, disc material not observed ultrasonographically was still present after the second examination. In these two cases, the disc material was either located near the uneven edges of the hemilaminectomy (which may have interfered with its visualization), or there was a small amount of material and no deviation of the parallel lines that define the spinal cord.

The authors are reluctant to speculate what the clinical significance of this residual disc material was, given that most of the signs associated with adequate decompression of the spinal cord were observed (Nakayama, 1993; Tanaka et al., 2005; Nanai et al., 2006). A study investigating postoperative presence of residual disc material in 40 dogs found that disc material remained within the vertebral canal in all dogs; however, this was not associated with inability to recover motor function of the pelvic limbs or voluntary bladder control (Roach et al., 2012). Furthermore, visualization of circulation (with power Doppler), central canal, and parallel lines representing the meninges, all compatible with adequate decompression of the spinal cord, have been identified in the presence of residual disc 


\section{Bonelli et al.}

material after surgical decompression and removal of the greater part of extruded disc (Nanai et al., 2007). Other observations related to decompression of the spinal cord such as

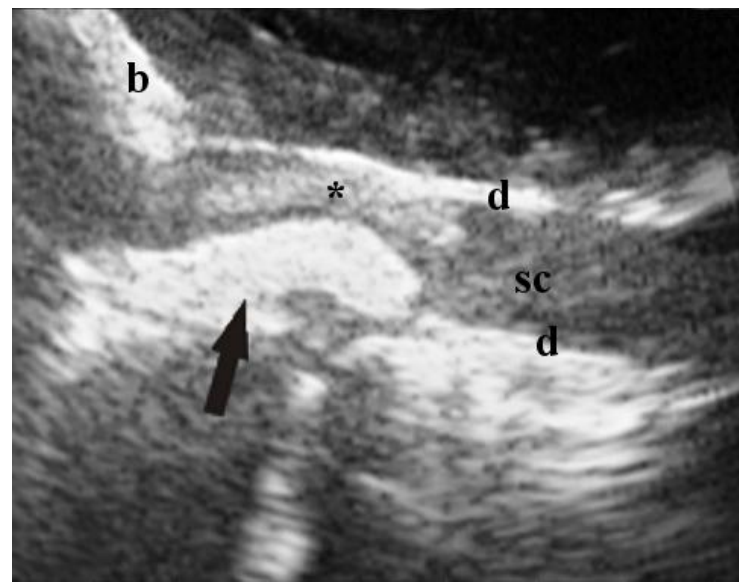

Figure 1. Sagittal ultrasonographic view following hemilaminectomy at $\mathrm{L}_{2-3}$ showing an extruded intervertebral disc (arrow) in dog 5. Note the hyperechogenicity $(*)$ present at the area of spinal cord compression, deviation of the ventral meningeal line, and inability to clearly visualize the central canal. sc, spinal cord; $d$, meninges; $b$, bone.

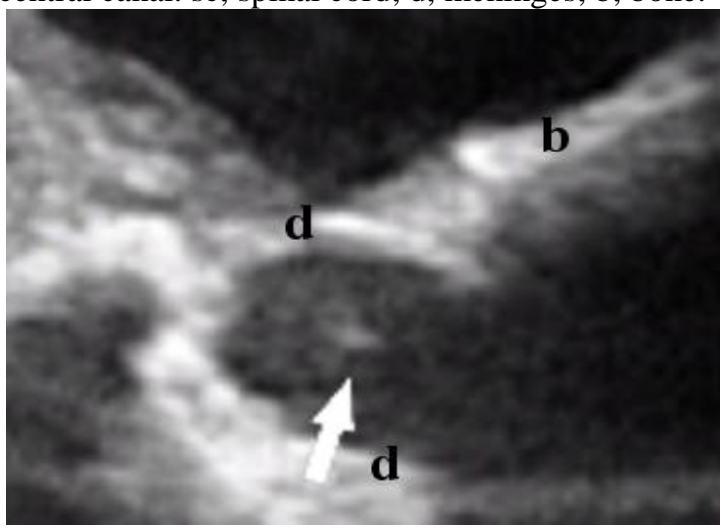

Figure 3. Transverse image of the same dog as Fig. 1, after removal of the extruded disc material. The central canal is visible (arrow). d, meninges; $b$, bone.

In one dog, the hemilaminectomy was mistakenly done at $\mathrm{T}_{13}-\mathrm{L}_{1}$. When no signs of compression or disc material appeared on ultrasound examination, the hemilaminectomy was extended to $T_{12-13}$. At this new location, disc material was present and the central canal was less defined at the site of disc extrusion. pulsation of the spinal cord on M-mode (Nakayama, 1993) and on B-mode (Nanai et al., 2006) were not investigated herein.

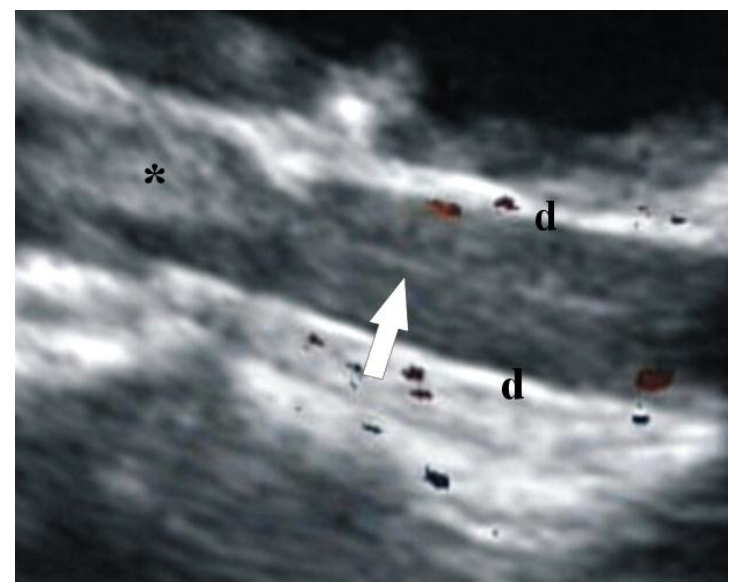

Figure 2. Same dog as Fig. 1, after removal of the extruded disc material. The central canal (arrow) is visible just caudal to the still present hyperechoic area $(*)$. At the moment of image capture, color Doppler is not showing any vessels. $d$, meninges; $b$, bone.

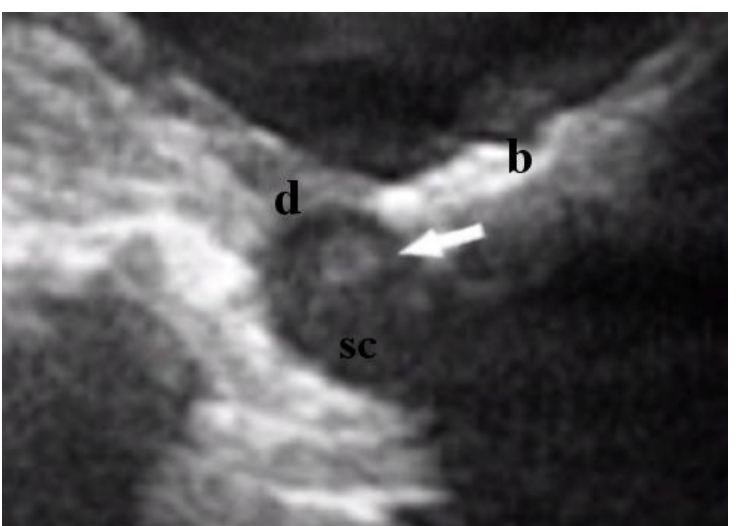

Figure 4. Transverse image of the same dog as Fig. 1, after removal of the extruded material, showing increased echogenicity in spinal cord parenchyma (arrow). sc, spinal cord; d, meninges; b, bone.

In seven dogs the extruded disc material was located laterally, in a position that made it visible and sometimes externalized when the hemilaminectomy was created, which may justify the absence of signs of a severe compression of the spinal cord on ultrasonographic examination. Under these circumstances, the hemilaminectomy would have 
allowed for some accommodation of the material and thus relieved its pressure on the spinal cord.

In all three dogs with fracture/luxation of the thoracolumbar spine, there was malalignment of the vertebral floor prior to stabilization. In two dogs, vascularization was observed with the use of color Doppler in the section of spinal cord that appeared to be normal, just cranial to the site of the fracture where a hyperechoic image obliterated the view of the spinal cord (Figure 5).
Trauma occurred between 7 and 20 days prior to surgery, and none of the dogs had presence of deep pain upon neurologic examination. Surgery was performed because of local pain and/or instability.

No bone fragments were identified within the vertebral canal, though visualization of the caudal portion of the exposed area was impaired by the fibrosis presence. One of the dogs had a hyperechoic area just cranial to the fracture site.

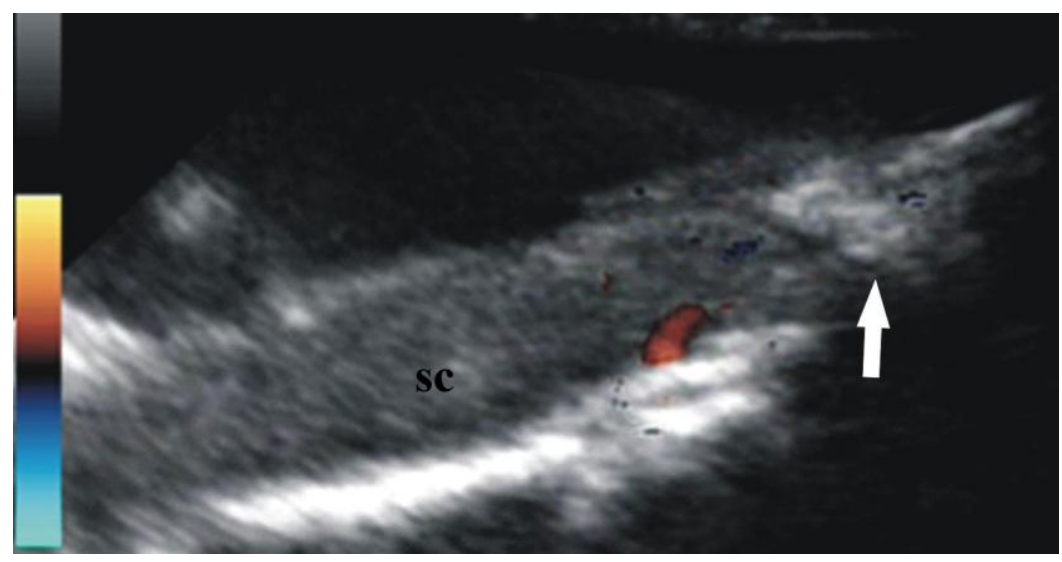

Figure 5. Sagittal ultrasonographic image of the spinal cord of a dog with a $\mathrm{T}_{11-12}$ fracture following laminectomy. Note the heterogenous hyperechoic image identified as fibrosis (arrow) caudal to the hypoechoic spinal cord. In red, vascularization seen with color Doppler. sc, spinal cord.

In the dogs with vertebral fractures, dislocation of the vertebral canal and inability to visualize vascularization with Doppler were considered indicative of a poor prognosis for neurological recovery, though a clear relationship between ultrasonographic findings and prognosis has not been established (Nakayama, 1993; Nanai et al., 2007). In fact, imaging diagnostics can only go so far in reflecting a patient's neurological condition as there are cases where dogs with $100 \%$ dislocation of the vertebral canal had deep pain and recovered ambulation (Araújo et al., 2012). Furthermore, spinal walk should be taken into consideration when discussing prognosis. One dog in this study recovered some ambulation 120 days after surgery but without nociception, which is consistent with spinal walk.

In the two cases of thoracolumbar fracture surgery in which color Doppler was used, vascularization of the spinal cord up to the site of the fracture and a lack of circulation immediately caudal to that area was confirmed, suggesting necrosis of that section of the spinal cord. Focal myelomalacia has been previously described (Tanaka et al., 2006), but there are no descriptions of lack of circulation and fibrosis after suspected spinal cord transection in the investigated veterinary literature. Visualization of circulation cranial to that point suggested that the angulation of the transducer was adequate and was thus reliable in detecting a lack of vascularization past the lesion site. This was also supported by the neurological exam, which indicated a lack of nociception caudal to that location.

In the second dog, the spinal cord was seen on transverse images up to the point where it disappeared completely, substituted by a hyperechoic heterogeneous image consistent with the presence of fibrosis. This confirmed the observation made by the surgical team that the spinal cord had been transected. 
None of the three dogs with thoracolumbar fracture/luxation had images compatible with the presence of bony fragments within the vertebral canal, namely hyperechoic structures with acoustic shadowing (Kramer et al., 2012).

The area of the spinal cord observed as hyperechoic to normal spinal cord parenchyma in five dogs (four with extruded disc and one with a thoracolumbar fracture) near the site of the lesion may be due to hemorrhage or focal myelomalacia (Nakayama, 1993).

Regarding the two dogs with neoplasia, the first dog had a loss of bone density seen at the level of $\mathrm{L}_{5}$ on radiographic examination. On the ultrasound, the vertebrae in question appeared hypoechoic, allowing the passage of sound waves through the bone and subsequent visualization of the cancellous bone within the vertebral body. There was also a dorsal curvature of the floor of the vertebral canal at this point, with dorsal dislocation of the spinal cord (Fig. 6).

After removal of most of the material, a second ultrasonographic examination showed that part of the altered tissue remained below the spinal cord. There was less of a dorsal dislocation of the spinal cord. A decision not to remove more of the vertebral body was made, even though altered tissue was still seen on ultrasound, due to the risk of generating more instability. Biopsies were collected and histopathology confirmed a diagnosis of osteoblastic osteosarcoma.

The second dog showed a dislocation of the spinal cord and the image was consistent with a mass within the vertebral canal on contrast CT. The greatest compression was located at $\mathrm{L}_{2}$. After hemilaminectomy, a mass was seen at the site of the defect, in contact with the spinal cord. On the ultrasound, an elongated heterogeneous mass was observed over the spinal cord. There was no significant deviation of the hyperechoic limits of the spinal cord and no sign of cord compression even though it had been observed on CT. This suggested that the hemilaminectomy performed directly over the compressing agent resulted in some degree of decompression. Fragments were sent for histopathological analysis and the neoplasia was characterized as a chondroma.

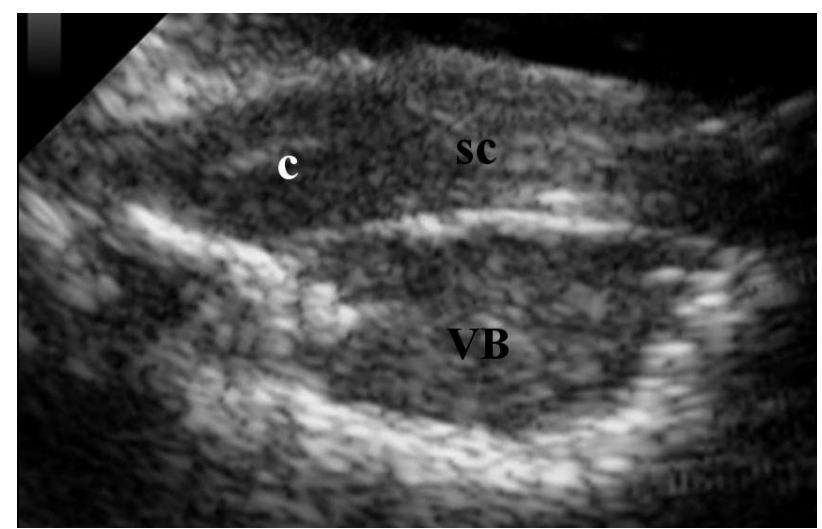

Figure 6. Sagittal ultrasonographic image of the spinal cord after laminectomy at $\mathrm{T}_{12}$, showing the spinal cord (sc) as it is dislocated dorsally by an altered and hypoechoic vertebral body (VB) due to neoplasia. Note that the central canal (c) is no longer visible directly over the compression.

In both dogs that underwent surgery due to compression of the spinal cord by neoplasia, IOS was able to identify that there was no involvement of the spinal cord. Thus the neoplasia could be dissected from the spinal cord and meninges. The main advantage in using IOS during removal of spinal tumors is precisely the clear evaluation of the extent of the altered parenchyma within the cord, if any, and differentiating between intra and extradural compressions (Tanaka et al., 2006; Nanai et al., 2007)

As for visualization of the cauda equina, it was impaired by the presence of fibrosis around the nerve roots in all three dogs and was characterized as an amorphous, heterogenous, hyperechoic mass. In one dog, thin hypoechoic "tracts" were observed within the fibrosis on sagittal view. Ultrasound allowed identification 
of the vertebral canal and its malalignment in all three dogs. The conus medullaris was observed in one of the dogs.

The presence of fibrosis in the three dogs that underwent surgery for decompression of cauda equina is consistent with fracture healing at $\mathrm{L}_{7}-\mathrm{S}_{1}$ (which occurred between 1 and 11 months prior). The surgeons did not have a clear view of the vertebral canal, and ultrasound was able to show the uneven floor of the canal and the fibrous tissue which encompassed the canal and, consequently, the nerve roots.

The ultrasonographic appearance of the cauda equina has been described in humans (Montalvo and Falcone, 1999), but similar images could not be obtained in these three dogs. Hypoechoic "tracts" observed longitudinally within the fibrotic tissue on sagittal view in one dog were thought to be the cauda equina, but a clear image was not obtained. The value of IOS during surgical management of cauda equina syndrome requires further investigation because the surgeon can usually see the entire vertebral floor macroscopically.

Previous reports have indicated that transverse images may be difficult to obtain because of the size of the transducer relative to the surgical site (Tanaka et al., 2006; Nanai et al., 2007). During a pilot study, there was difficulty positioning a linear transducer $(4.5 \mathrm{~cm}$ in width) to obtain a transverse image through the hemilaminectomy site. Therefore, a convex transducer was selected for its smaller size and better fit into the

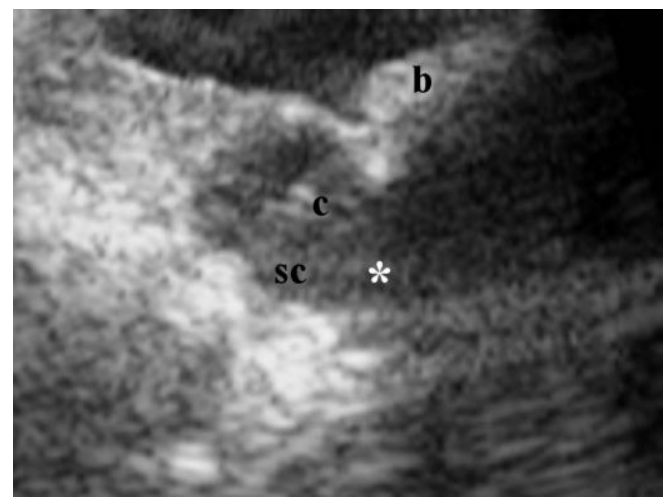

Figure 7. Transverse ultrasonographic view of the spinal cord (sc) of a dog after removal of extruded disc material at the level of $\mathrm{L}_{2-3}$. c, central canal; b, bone. Note the acoustic shadowing of the distal edge of the cord $(*)$. operative site. But even then, transverse images obtained through a hemilaminectomy often lost definition of the area of the spinal cord farthest from the opening because angulation of the transducer yielded an acoustic shadow from the bony edge (Fig. 7). A laminectomy allowed greater mobility of the transducer and did not restrict the access and angulation (Fig. 8). The use of elastic wrap for fastening the surgical gloves to the transducer facilitated maneuverability within the surgical field because the knotted gauze added bulk to the ensemble. It is important to keep in mind that the angulation of the transducer will affect the image obtained, and the spinal cord seen through the hemilaminectomy appears angulated.

The presence of circulation as seen on Doppler, which has also been considered a sign of decompression of the spinal cord (Nanai et al., 2006) was not observed in all dogs. Observations with color Doppler were not performed after decompression in four of the dogs. Three of them were unstable at the time, and a decision was made not to prolong anesthesia for a second ultrasonographic examination. The fourth dog had neither a first nor second view using color Doppler because it was not available at the time. Of the nine dogs on which color Doppler was used during the second ultrasound, only one had no visible circulation, even though it had nociception. This may be because the surgical field did not allow for proper positioning of the transducer at an angle required for an adequate reflection of the sound waves off the blood cells circulating in the vessels of the spinal cord.

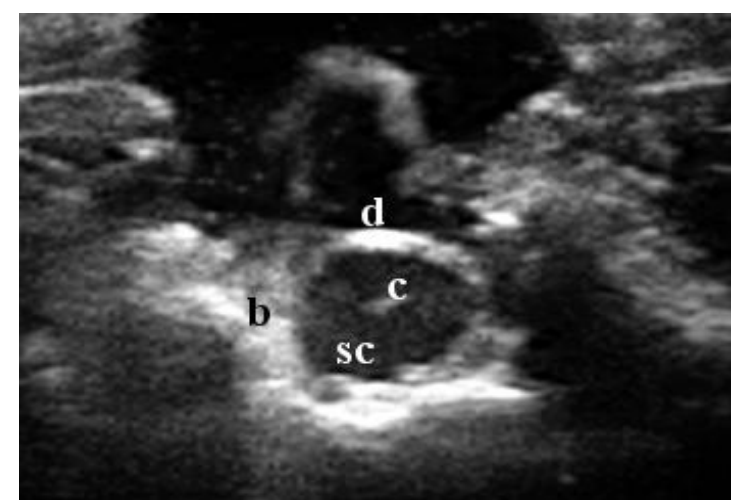

Figure 8. Transverse ultrasonographic view of the spinal cord (sc) of a cadaver dog obtained via a laminectomy during the pilot study. c, central canal; $\mathrm{d}$, meninges; $\mathrm{b}$, bone. 
The surgical team's main concerns were that use of IOS would increase both the duration of the surgical procedure and risk of infection. To address the former, preparation of the transducer was synchronized with the start of the surgery and while the ultrasonographic examinations did increase surgical time, each exam was approximately $8 \pm 3$ minutes long, which was considered acceptable. Furthermore, none of the dogs in this study developed post-operative infections, indicating that the aseptic measures adapted from existing literature (Finn-Bodner et al., 1995; Nanai et al., 2006), were sufficient.

Preoperative CT or magnetic resonance imaging (MRI) can help locate the site and side of disc extrusion and suggest the extent of the surgical opening, but IOS is the only available method in veterinary medicine for providing real-time observations which may alter the surgical procedure (Nakayama, 1993). Although IOS was not paramount for locating the side of the compression when a specific location had been obtained via CT (10 of the 13 dogs with disc extrusion), when material was located ventral to the spinal cord, ultrasonographic examination prior to its removal was more beneficial because the surgeon was not otherwise able to see the material (Nanai et al., 2007). It also showed alterations in the spinal cord parenchyma that had not been observed on CT in four dogs.

Regarding its influence on decision-making during surgery, IOS was more valuable when the cause of compression was hidden from the surgeon's view by the spinal cord, as has been previously described (Nanai et al., 2007). In the cases reported herein, the approach was done on the side of the extrusion in all lateral disc extrusions, and no compressive material was present on the other side of the spinal cord. In one case, IOS showed signs compatible with a slight disc protrusion (convex shape pushing the ventral limits of the spinal cord dorsally), which substantiated the surgeon's decision to fenestrate that disc. Even when there was no compression on the far side of the spinal cord, IOS contributed to the overall procedure because it showed there was no compression outside the immediate view of the surgeon, thus reducing the amount of manipulation and risk of injury to the spinal cord. Most importantly, IOS successfully confirmed adequate decompression of the spinal cord in all 11 dogs examined a second time, in accordance with previous reports (Nakayama, 1993; Nanai et al., 2007).

As for the three dogs on which no second ultrasound examination was performed, one had severe bleeding and required the use of a hemostatic absorbable gelatin sponge, which appeared as a hyperechoic material that impeded the view of the spinal cord, similar to gelatin powder (Quencer and Montalvo, 1984). Bleeding interfered with visualization of the structures within the vertebral canal (Kramer et al., 2011), but it was not considered an impediment when it was controllable.

Limitations of the use of IOS for evaluation of the spinal cord are its restriction to surgical procedures where there is a large enough opening to the vertebral canal for images to be obtained (Tanaka et al., 2006), so windows obtained via foraminotomies, fenestration, minihemilaminectomies or corpectomies would not be adequate (Kramer et al., 2012). An available device, a veterinarian with knowledge of the device and procedure, and sterile gel are also required for the application of IOS. In-house sterilization of ultrasound gel and training of members of the surgical team to perform the exam solved some of the issues, but scheduling was the authors' greatest obstacle.

A previous report using a teaching model in human medicine suggested that some knowledge can be obtained regarding the ultrasonographic appearance of the vertebral canal after short sessions. Surgeons (with no particular experience in ultrasonography and regardless of surgical experience) were able to recognize several degrees of vertebral canal stenosis (Fritz et al., 2000). A pilot study using seven cadavers was found to be adequate in familiarizing the operator with the normal anatomy of the spinal cord and vertebral canal. Fat and bone fragments were inserted into the vertebral canal to mimic alterations, but there was still a learning curve. For this reason, an experienced ultrasonographer aided in identifying the alterations during the spinal surgeries. However, it is the authors' belief that surgical personnel can be trained to perform intraoperative spinal sonography. 


\section{CONCLUSIONS}

Intraoperative ultrasonography was feasible and able to contribute information during surgery for spinal cord or cauda equina decompression and for fracture reduction and/or stabilization. The principle advantages of intraoperative ultrasonography were estimating the vascularization and extent of the spinal cord lesion. Most importantly, it allowed real time evaluation of the spinal cord and conditions related to the vertebral canal, which permitted modification of the surgical procedure.

\section{ACKNOWLEDGEMENTS}

Financial aid was received by the main author from the National Counsel of Technological and Scientific Development (CNPq).

\section{REFERENCES}

ARAÚJO, B.M.; SILVA, A.C.; FIGUEIREDO, M.L. et al. Functional recovery of two dogs with caudal thoracic fractures and luxations with $100 \%$ deviation of the vertebral canal. MEDVEP, Rev. Cient. Med. Vet. Peq. Anim. Anim. Estim., v.10, p.372-377, 2012.

FINN-BODNER, S.T.; HUDSON, J.A.; COATES, J.R. et al. Ultrasonographic anatomy of the normal canine spinal cord and correlation with histopathology after induced spinal cord trauma. Vet. Radiol. Ultrasound, v.1, p. 39-48, 1995.

FRITZ, T.; KLEIN, A.; KRIEGLSTEIN, C. et al. Teaching model for intraoperative spinal sonography in spinal fractures. An experimental study. Arch. Orthop. Trauma Surg., v.120, p.183-187, 2000.

GALLOWAY, A.M.; CURTIS, N.C.; SOMMERLAD, S.F.; WATT, P.R. Correlative imaging findings in seven dogs and one cat with spinal arachnoid cysts. Vet. Radiol. Ultrasound, v.40, p.445-452, 1999.

KRAMER, M.; GOLLA, T.; SCHMIDT, M.J. Intraoperative sonography for examination of disk extrusion in the dog. Tierarztl. Prax, v.39, p.397-403, 2011.
KRAMER, M.; GOLLA, T.; SCHMIDT, M.J. Intraoperative spinal cord ultrasonography in dogs -limitations \& possibilities-. In: EUROPEAN SOCIETY OF VETERINARY ORTHOPAEDICS AND TRAUMATOLOGY CONGRESS, 16., 2012, Bologna. Proceedings... Bologna: [s.n.], 2012. p.253-255.

MONTALVO, B.M.; FALCONE, S. Sonografia Intraoperatória da Espinha. In: RUMACK, C.M.; WILSON, S.R.; CHARBONEAU, J.W. (Eds). Tratado de ultra-sonografia diagnóstica. 2.ed. Rio de Janeiro: Guanabara Koogan, 1999. p.554568.

NAISH, C.; MITCHELL, R.; INNES, J. et al. Ultrasound imaging of the intervertebral disc. Spine, v.28, p.107-13, 2003.

NAKAYAMA M. Intraoperative spinal ultrasonography in dogs: normal findings and case-history reports. Vet. Radiol. Ultrasound, v.34, p.264-268, 1993.

NANAI, B.; LYMAN, R.; BICHSEL, P.S. Intraoperative use of ultrasonography during continuous dorsal laminectomy in two dogs with caudal cervical vertebral instability and malformation ("Wobbler syndrome"). Vet. Surg., v.35, p.465-469, 2006.

NANAI, B.; LYMAN, R.; BICHSEL, P.S. Use of intraoperative ultrasonography in canine spinal cord lesions. Vet. Radiol. Ultrasound, v.48, p.254-261, 2007.

QUENCER, R.M.; MONTALVO, B.M. Normal intraoperative spinal sonography. Am. J. Roentgenol., v.143, p.1301-1305, 1984.

ROACH, W.J.; THOMAS, M.; WEH, J.M. et al. Residual herniated disc material following hemilaminectomy in chondrodystrophic dogs with thoracolumbar intervertebral disc disease. Vet. Comp. Orthop. Traumatol. v.25, p.109-115, 2012.

TANAKA, H.; NAKAYAMA, M.; ORI, J.; TAKASE, K. Usefulness of intraoperative ultrasonography for two dogs with spinal disease. J. Vet. Med. Sci., v.67, p.727-730, 2005.

TANAKA, H.; NAKAYAMA, M.; TAKASE, K. Intraoperative ultrasonography in two dogs with spinal disease. Vet. Radiol. Ultrasound, v.47, p.99-102, 2006. 